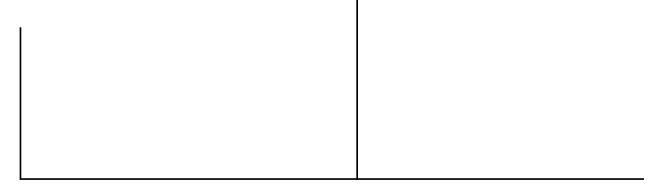

Rev. Latinoam. Psicop. Fund. VI, 1, 154-164

\title{
Evolução e dissolução do sistema nervoso*
}

\author{
John Hughlings Jackson
}

\begin{abstract}
Primeiramente, gostaria de agradecer ao Senhor Presidente pelo convite para essa série de palestras.

A doutrina da evolução ganha, dia-a-dia, novos adeptos. Não se trata simplesmente de um sinônimo de Darwinismo. Herbert Spencer aplica-a a toda ordem de fenômenos. A aplicação desta teoria, por Herbert Spencer, no sistema nervoso é de suma importância para os estudiosos da medicina. Penso, há muito tempo, que seria de grande ajuda nas investigações das patologias do sistema nervoso, se as considerássemos como o reverso do processo de evolução, ou seja, como dissoluções. Dissolução é o termo que empresto de Spencer para designar o reverso do processo de evolução.

Este tema é estudado há muitos anos. Há cerca de meio século, Laycock aplicou a doutrina de ação reflexa ao cérebro.
\end{abstract}

* Primeira palestra. Palestras realizadas no Royal College of Physicians em março de 1884. Fonte: JACKSON, J. H., Selected writings of John Hughlings Jackson - Vol. 2 (Edited by James Taylor), Londres, Hodder and Stoughton, 1932, p. 45-53. Originalmente publicado no British Medical Journal, 1884, i, p. 591-660.

Tradução de Daniela Kurcgant. Revisão técnica do Prof. Dr. Mário Eduardo Costa Pereira, do Laboratório de Psicopatologia Fundamental da UNICAMP. 
Sir Charles Bell, ao expor os graus de intoxicação por álcool, e Baillarger, ao estudar as afasias, apontaram para uma redução do mais voluntário para o mais automático. As últimas pesquisas do Dr. Anstie (Estimulantes e Narcóticos) são as de maior valor entre as contribuições para os estudos das doenças do sistema nervoso como exemplos de dissolução, embora ele não utilize este termo. Refirome também, com grande respeito, aos estudos de grande valor e originalidade que Ross, Ribot e Mercier realizaram nesta mesma direção. As pesquisas brilhantes de Hitzig e Ferrier, além da óbvia contribuição em outras direções, são de grande valor na confirmação das doutrinas de evolução e dissolução do sistema nervoso. Nesta mesma linha de orientação menciono, com enorme respeito, a recente contribuição de um artigo sobre localização cerebral do Dr. Sharkey.

No ensejo de fornecer ilustrações sobre a dissolução o mais rápido possível, procurarei tecer considerações preliminares curtas. Falo somente sobre os aspectos mais marcantes da evolução e da dissolução, deixando de lado outros fatores importantes verificados por Herbert Spencer. Infelizmente, o tempo escasso faz com que eu simplifique meu tema por meio de sérias omissões. Spencer, a quem devo as minhas mais profundas obrigações, não deve ser julgado pela presente aplicação de suas doutrinas, ou por partes delas. Peço desculpas pelo uso de termos populares. A terminologia "mais voluntário”, embora pareça um termo técnico, é, quando utilizado em contraste com o "mais automático", um termo popular. ${ }^{1}$ Posteriormente, ela será descartada. Devo também informar sobre uma omissão; falo, na maioria das vezes, somente sobre o sistema cerebral, quase que ignorando todas as divisões do sistema cerebelar. Para o presente estudo, deixo de lado a distinção absoluta que realmente existe entre os estados mentais e nervosos.

Iniciando pela evolução, e lidando somente com as partes mais evidentes do processo, podemos dizer que se trata de um desenvolvimento ascendente, dentro de uma ordem particular. Faço três observações que, embora partam de diferentes ângulos, são quase a mesma coisa: (I) Evolução é a passagem do mais para o menos organizado; ou seja, dos centros inferiores, melhor organizados, em direção aos centros superiores, menos organizados; colocando-se de outra forma, o progresso ocorre de centros comparativamente melhor organizados ao nascimento em direção aos centros superiores que, continuamente, se organizam ao longo da vida. (2) Evolução é a passagem do mais simples para o mais complexo; novamente, dos centros inferiores para os superiores. Não há

1. O autor utiliza os termos "most voluntary" e "most automatic". As aspas foram colocadas pelo próprio autor. 
inconsistência em se conceber centros que sejam ao mesmo tempo mais complexos e menos organizados. Pressupõe-se um centro constituído por dois elementos sensórios e dois elementos motores; se os elementos sensórios e motores forem bem ajustados, a "corrente flui" facilmente dos elementos sensórios para os motores. Assim, o centro, apesar de muito simples, é altamente organizado. Por outro lado, podemos conceber um centro constituído por quatro elementos sensórios e quatro elementos motores, nos quais, entretanto, as junções entre os elementos sensórios e motores são tão imperfeitas que a corrente nervosa encontra muita resistência. Neste caso, encontramos um centro duas vezes mais complexo que o referido anteriormente, mas cuja organização é a metade do anterior. (3) Evolução é a passagem do mais automático para o mais voluntário.

A tripla conclusão alcançada é a que os centros superiores, que são o clímax da evolução nervosa, e que constituem o "órgão da mente” (ou a base física da consciência), são os menos organizados, mais complexos e mais voluntários. Assim, o processo positivo, no qual o sistema nervoso "acrescenta” é chamado de evolução, e o processo negativo de "retirar” é a dissolução.

A dissolução, por ser o reverso do processo de evolução, necessita de poucos esclarecimentos. Trata-se de um processo oposto ao desenvolvimento; trata-se de uma decomposição do menos organizado, mais complexo e mais voluntário em direção ao mais organizado, mais simples e mais automático. Eu utilizei o termo “em direção” porque se a dissolução incluísse o mais organizado, mais simples, etc.; em outras palavras, se a dissolução fosse total, o resultado seria a morte. Nada mencionarei sobre dissolução total nesta palestra. Portanto, por ser parcial, a dissolução, em todos os casos, será sempre dupla. A própria sintomatologia das doenças nervosas é uma condição dupla; há um elemento positivo e um elemento negativo em todos os casos. Já que nos casos de doença, a evolução não foi totalmente revertida, restará sempre algum grau de evolução. Assim, a regra "para o grau de dissolução subseqüente” equivale, estritamente, à regra "ser reduzido a um nível inferior de evolução"; com maiores detalhes: a perda do menos organizado, mais complexo e mais voluntário implica na retenção subseqüente do mais organizado, do menos complexo, e do mais automático. Não se trata de uma regra óbvia, ou, se for, é muito comumente negligenciada. A doença é entendida como a "causa" dos sintomas de insanidade. Considero que a doença somente produz sintomas mentais negativos respondendo à dissolução, e que todos os sintomas mentais positivos elaborados (ilusões, alucinações, delírios, e comportamentos extravagantes) são resultados da atividade dos elementos nervosos não acometidos pelo processo patológico. Este princípio pode ser ilustrado de outra forma: iniciando-se, desta vez, com o estado saudável. A idéia é que os pensamentos e comportamentos normais de cada pessoa 
são, ou significam, a sobrevivência do estado mais "forte", ${ }^{2}$ do que se poderia chamar da "camada” mais superior dos centros superiores: o nível máximo superior normal de evolução. Agora, supondo-se que em função de alguma doença este nível máximo superior normal de evolução tenha suas funções prejudicadas, ocorre a dissolução que corresponde aos sintomas negativos da insanidade mental. Argumento ainda que os sintomas mentais positivos são a sobrevivência dos estados mais "fortes" dos níveis mais inferiores de evolução que foram poupados. Os pensamentos mais absurdos e as ações mais extravagantes das pessoas insanas são decorrentes da sobrevivência de seus estados mais "fortes". Falo em "mais fortes”, não em "melhores”, o que, no evolucionismo, não tem relação com bom ou ruim. O homem insano acredita naquilo que chamamos de ilusões; são as suas percepções. Suas ilusões, etc. não são causadas pela doença, mas são resultado da atividade cerebral que lhe foi deixada (o que a doença lhe poupou).

Após este breve esquema, menciono o que poderia ser um retrospecto. Todo caso de dissolução corresponde ao exato oposto da evolução. Entretanto, freqüentemente, poderíamos encontrar situações de opostos aproximados. Procurarei esclarecer eventuais dificuldades. Dividimos os casos de dissolução em dois grandes grupos: uniforme e local.

Na dissolução Uniforme todo o sistema nervoso está submetido às mesmas condições ou influências malignas; a evolução de todo o sistema nervoso está comparativamente revertida. Nestes casos, todo o sistema nervoso é "reduzido", mas os diferentes centros não são igualmente atingidos. Um agente tóxico, como o álcool, distribui-se por todas as partes; mas os centros superiores, sendo menos organizados, são atingidos primeira e mais intensamente; os centros médios, sendo mais organizados, resistem mais que os anteriores, e os centros inferiores, sendo os mais organizados, resistem mais que os demais. Se os centros inferiores para a respiração e a circulação não resistissem mais que os centros superiores, a morte por álcool seria algo muito comum. Uma outra forma de abordagem é pensar que a ascensão da dissolução uniforme segue uma "ordem composta". Os estágios podem, assim, ser simbolizados pelo uso das letras iniciais de superior, médio e inferior. O primeiro estágio de dissolução corresponde a $s$; o segundo a $s^{2}+m$; o terceiro estágio a $s^{3}+m^{2}+i$, etc. Falarei pouco sobre o envolvimento dos centros médios e inferiores nos casos de dissolução uniforme, pois o mais importante, especialmente no que diz respeito às noções de localização, é reconhecer que a ordem da dissolução é uma ordem composta.

2. O autor utiliza o termo "survival of the fittest” que, em geral, em português, é traduzido por "sobrevivência do mais forte”. 
A outra divisão é a dissolução Local. Evidentemente, a doença de uma parte do sistema nervoso não poderia acarretar o reverso da evolução na totalidade do sistema. Tudo o que podemos esperar é o reverso local da evolução, uma vez que deveria ocorrer uma perda do mais voluntário em direção ao mais automático naquilo que a parte doente, acometida, representa. Novamente, o que foi dito na dissolução uniforme acontece somente quando a dissolução ocorre em todas as divisões dos centros superiores, quando se dá uma redução do mais voluntário de todos os centros para o mais automático de todos. A dissolução, embora local, pode ser de diferentes maneiras. A doença pode atingir qualquer nível de evolução, de um lado, ou ambos os lados; pode afetar os elementos sensoriais ou motores. Deve ser particularmente mencionada a ocorrência de dissoluções locais nos centros superiores. Há concordância quando se considera que em todos os casos de insanidade os centros superiores estão morbidamente afetados. Assim, mesmo existindo diferentes tipos e graus de insanidade como, por exemplo, a paralisia geral progressiva e a melancolia, faz-se necessário nos dois casos que as diferentes divisões dos centros superiores sejam morbidamente atingidas. Os diferentes casos de insanidade ocorrem por diferentes dissoluções locais dos centros superiores.

Agora darei alguns exemplos de dissolução. Confesso que selecionei casos que ilustram de forma bastante definitiva, pois não pretendo conseguir mostrar todos os casos da nossa larga experiência clínica para exemplificar a lei de dissolução. Entretanto, utilizo casos bastante comuns, ou seja, casos em que a patologia é bem conhecida. São casos cujas doenças acometem o sistema nervoso em diferentes níveis, do mais inferior ao mais superior, sendo, a maior parte deles, exemplos de dissolução local.

I. Iniciando pela parte inferior do sistema nervoso central, o primeiro exemplo é a variante mais comum de atrofia muscular progressiva. Vemos aqui que a atrofia começa no membro mais voluntário, o braço; afeta, primeiramente, a parte mais voluntária deste membro, a mão, e, primeiro de tudo, a parte mais voluntária da mão; espalha-se então pelo tronco e, em geral, para as regiões mais automáticas.

2. Caminhando para um nível mais superior, chegamos à hemiplegia por destruição de parte de um plexo na região cerebral média. Escolhendo a variante mais comum de hemiplegia, observamos perda maior ou menor dos movimentos voluntários em um lado do corpo. Encontramos, no braço, o membro mais voluntário, o sofrimento maior e mais extenso; encontramos também que a região mais voluntária da face é mais atingida que o restante da face. Neste caso devemos apontar, particularmente, para o nível inferior de evolução que permanece, restritamente falando, mais inferior e colateral. Observamos que, embora os 
movimentos unilaterais (os mais voluntários) estejam perdidos, os movimentos bilaterais, os mais automáticos, permanecem. Tempos atrás isto foi explicado por Broadbent e pesquisas clínicas subseqüentes estão de acordo com sua hipótese. Um ponto a ser considerado é que os movimentos bilaterais, nos casos de hemiplegia, apesar da destruição de alguns dos sistemas nervosos que os representam, ficam preservados. Estes movimentos são duplamente representados, pois são representados em cada metade do cérebro. Hemiplegia é um caso claro de dissolução, perda dos movimentos mais voluntários de um lado do corpo, com persistência dos movimentos automáticos.

3. A próxima ilustração é a chamada paralisia agitada. ${ }^{3}$ Apesar das especulações sobre a localização da doença, o distúrbio motor ilustra, muito bem, a dissolução. Na maioria dos casos, o tremor afeta, primeiramente, o braço, iniciando-se na mão, no polegar e no dedo indicador. O distúrbio motor, nesta doença, torna-se bilateral. Nos estados avançados, a paralisia agitada é dupla, ocorre a hemiplegia com rigidez - é a dissolução bilateral.

4. Em seguida falaremos das crises epileptiformes as quais, inquestionavelmente, pertencem às doenças que acometem as regiões cerebrais médias (centros motores médios). Levando em conta a variedade mais freqüente, observamos que o espasmo tem início, mais comumente, no braço, na parte mais próxima da mão e, mais constantemente no polegar e dedo indicador, ou em ambos. Estes dois dedos são as duas partes mais voluntárias de todo o corpo.

5. [As próximas ilustrações seriam casos de paralisias temporárias após crises epileptiformes]. ${ }^{4}$

6. A coréia é uma doença em que os membros, partes mais voluntárias, são afetados mais que o tronco, parte mais automática. Os braços, membros mais voluntários, são mais atingidos do que as pernas. A localização desta doença ainda não foi constatada. Entretanto, sob o ponto de vista dos sintomas, ilustra bem a dissolução. A coréia tem um interesse particular para mim, pois a grande elaboração dos movimentos, presente nesta doença, poderia corresponder a uma localização superior, a um nível superior de evolução. Há vinte anos, pensando em suas peculiaridades, ocorreu-me que as convoluções representavam movimentos - uma visão que tenho desde então.

7. A afasia também ilustra bem a doutrina de dissolução em várias direções. Consideremos um caso de perda completa da fala. (a) Ocorre uma perda da linguagem intelectual, considerada a linguagem mais voluntária, e a permanência

3. "Paralisia agitada” era o termo utilizado para a Doença de Parkinson.

4. Os colchetes foram utilizados pelo próprio autor. 
da linguagem emocional, que é a mais automática. Ao observarmos com mais cuidado, percebemos que o paciente não consegue falar e que sua pantomima está empobrecida. Entretanto, por outro lado, o paciente sorri, franze as sobrancelhas, muda o tom da voz (pode até cantar) e gesticula como sempre o fez. A gesticulação, que é uma manifestação emocional, deve ser diferenciada da pantomima, que é parte da linguagem intelectual. (b) A freqüente expressão dos termos "sim” e "não", nos casos de pacientes que antes estavam sem fala, é um fato de extrema significância. Observamos que os pacientes perderam a fala, com exceção das duas expressões verbais mais automáticas. As expressões "sim” e "não" são, de maneira geral, utilizadas automaticamente para consentir ou para negar quaisquer situações. Por conseqüência, são necessários arranjos nervosos altamente organizados e, portanto, profundamente automáticos. (c) Uma ilustração mais importante, mas não mais significativa, é a do paciente que não consegue falar, mas entende tudo o que lhe é dito. Facilmente este fato demonstra a perda da capacidade mais voluntária da linguagem com permanência da capacidade mais automática. (d) Assim, encontramos três graus de uso da expressão “não” pelos pacientes com afasia. Um paciente pode utilizá-lo apenas emocionalmente, o que é o mais automático. Outro paciente pode conseguir responder utilizando corretamente a expressão, o que é menos automático (aqui ocorre alguma conversa real). Há ainda um terceiro uso superior da expressão, que muitos afásicos não conseguem alcançar. São os casos de pacientes que conseguem responder "não” para uma questão, porém não conseguem dizer “não”, quando solicitados. Você pergunta ao afásico: “O seu nome é Jones?” O paciente responde: “Não.” Você pede para ele: “Repita: não!” O paciente tenta, mas não consegue. Então você pergunta ao paciente: "Você tem cem anos?” Ao que ele responde: “Não”. Então, novamente, você pede ao paciente: "Repita: não!” Ele tenta, mas não consegue. Nesse caso, a capacidade de linguagem para dizer "não" está prejudicada, mas a permanência do poder de resposta ilustra a dissolução. (e) Um paciente afásico pode ser incapaz de colocar a língua para fora quando solicitado. O paciente está consciente do que lhe é solicitado porque aponta com os dedos para a língua. A língua não está paralisada porque o paciente engole bem e porque, eventualmente, o paciente, sem perceber, põe a língua para fora. Aqui também ocorre uma redução para uma condição mais automática, em que há perda do movimento mais voluntário da língua, que é o de colocá-la para fora, quando solicitado.

8. Venho comentando até agora os casos de dissolução local que ocorrem em diferentes níveis, mas sempre em uma metade do sistema nervoso. No caso dos centros superiores, falarei de dissoluções uniformes, de casos em que todas as divisões dos centros estão submetidas às mesmas influências patológicas. 
Escolherei alguns casos de insanidade mental para tal finalidade. Ao fazer isto, escolho a mais difícil de todas as doenças nervosas. Concordo que não seja possível demonstrar, com detalhes, que as doenças mentais exemplifiquem o princípio de dissolução, mas selecionando os casos mais simples em direção aos mais complexos, poderemos ilustrá-lo. Começarei por um exemplo bastante comum, o delirum na doença não cerebral aguda. Esta, do ponto de vista científico, é um caso de insanidade. Neste caso, assim como em todos os casos de insanidade, é imperativo levar igualmente em conta não somente a dissolução, mas também o nível inferior de evolução que ainda resta. Na condição do paciente há uma parte negativa e outra parte positiva. Do ponto de vista negativo, ele não sabe que está no hospital e não reconhece as pessoas ao seu redor. Ele perde seus referenciais, ou, em termos equivalentes, ele está com a consciência prejudicada. Não devemos dizer-lhe que ele não sabe onde está porque sua consciência está prejudicada. O fato do paciente não saber onde está é, por si só, um déficit de consciência. O estado mental negativo significa, sob o ponto de vista físico, exaustão, ou perda da função dos centros nervosos superiores. Devemos dizer que tal fato aponta para a perda de função da "camada” mais superior do centro mais superior. Ninguém certamente acredita que os centros superiores, ou qualquer centro nervoso, sejam constituídos em camadas, mas esta suposição simplifica a explanação. A outra metade desta condição é positiva. Além da desorientação, os reconhecimentos do paciente são errados, falsos. Ele imagina a si mesmo como se estivesse em casa ou no trabalho; age e atua como se realmente assim estivesse. Não reconhece a enfermeira como tal, acha que é sua esposa. Esta, que é a parte positiva de sua condição, demonstra atividade da segunda camada dos centros nervosos superiores. Uma vez que a camada normal mais superior está sem funcionar, a segunda camada passa a ser, então, a mais superior. Seu delirium é a "sobrevivência do estado mais forte”. Assim, o paciente está reduzido a uma condição mais automática. Do ponto de vista negativo, perdeu suas referências “reais", perdeu suas funções mais superiores, mais recentes e menos organizadas. Do ponto de vista positivo, o paciente fala e age, como se estivesse ajustado a um referencial anterior "ideal”, necessariamente mais organizado.

Teço, então, algumas considerações sobre as oito ilustrações para evitar mal-entendidos. Reitero, novamente, que cada um dos oito casos apresentados de doença é uma dissolução diferente. Tudo o que se pretende apontar é que cada caso mostre uma redução, do mais voluntário em direção ao mais automático, no qual o centro nervoso envolvido, total ou parcialmente acometido pela patologia, apresente manifestações particulares. Se pegarmos casos extremos como o caso da atrofia muscular progressiva e o caso de insanidade (delirium 
na doença não cerebral aguda), diríamos que os dois casos são parecidos porque, em cada um, ocorre redução para uma condição mais automática. Poderíamos dizer também que são muito diferentes porque as partes do sistema nervoso, morbidamente afetadas, são muito diferentes.

Tenho até agora ignorado a distinção entre os estados nervosos e mentais. Se os casos de insanidade fossem considerados somente como um conjunto de fenômenos mentais, seria um absurdo compará-los com a atrofia muscular progressiva, que seria considerada somente um conjunto de fenômenos físicos. Entretanto, nenhuma dificuldade aparece se a insanidade mental ou "doença da alma” for entendida como a doença dos centros nervosos mais superiores, revelando-se por um conjunto de fenômenos mentais. Nesta direção, comparamos as doenças dos centros nervosos mais superiores com as doenças dos cornos anteriores (em centros mais inferiores), que se manifestam pela atrofia dos músculos correspondentes. Ao tomarmos conhecimento disto, poderíamos dizer que as duas situações clínicas são tão diferentes, que seria uma frivolidade compará-las. Ninguém pode negar que cada qual é uma afecção mórbida singular do sistema nervoso central. Alguém poderia ainda insistir na extrema diferença das afecções já que uma lesão está localizada em região bastante superior e outra em região bastante inferior do sistema nervoso central. Assim, poderíamos pensar que a classificação, baseada no princípio da dissolução, é verdadeira, mas sem valor; ou seja, não haveria utilidade em compor uma série ordenada ascendente, que iria da atrofia muscular progressiva à insanidade mental. Não haveria necessidade em demonstrar que a atrofia muscular progressiva é a redução para uma condição mais automática em um corno em nível inferior; que a hemiplegia é esta mesma redução, em maior escala, em um nível superior; e que a insanidade mental seria esta mesma redução no nível mais elevado do sistema nervoso, em uma escala ainda maior. Considero que esta classificação não tem um valor direto, mas, penso sim, um valor indireto, com enorme importância clínica. Precisamos, em nossa profissão, de dois tipos de classificações. O uso dos dois tipos de classificação será facilmente ilustrado pela classificação, ou, estritamente falando, por um agrupamento de plantas, realizada pelo fazendeiro, por razões práticas, e outra classificação das plantas realizada pelo botânico, para o avanço da biologia. Concordo que seria um erro classificar juntas a atrofia muscular progressiva e a insanidade mental. Seria como classificar conjuntamente bambu e grama. Tal classificação de plantas seria um absurdo em uma fazenda ou em um jardim. Assim, a classificação das doenças do sistema nervoso, baseada no princípio da dissolução, seria absurda em um hospital ou na enfermaria de um asilo. Não sei outro caminho, a não ser a doutrina da evolução, nos quais os casos de insanidade mental - doenças dos centros nervosos superiores - possam ser 
comparativamente estudadas com doenças não mentais do sistema nervoso doenças dos centros nervosos inferiores.

Falarei das diferentes profundidades de dissoluções particulares. Quanto mais profunda a dissolução, mais superficial o nível de evolução remanescente. Na hemiplegia, em função de uma lesão na cápsula interna, ocorre, de acordo com a gravidade da lesão, três graus de profundidade. (Certamente, a divisão em três graus é arbitrária.) No primeiro grau, há alguma paralisia da face, braço e perna; no segundo grau, a paralisia destas partes é mais intensa e, além disso, abrange maior extensão do corpo - a cabeça e os olhos do paciente estão voltados para o lado paralisado. Trata-se aqui de uma ilustração que chamei de "ordem composta”. A diferença entre os dois graus é não somente a paralisia mais intensa, nem apenas a maior extensão na paralisia no segundo grau, mas ambos os aspectos; há mais paralisia das partes afetadas e extensão da intensidade da paralisia para partes além delas. Uma doutrina adequada de localização deve levar em conta a "ordem composta" no aumento da gravidade das lesões. Assim, no terceiro grau de hemiplegia ocorre uma imobilidade universal. Neste grau, o paciente perdeu a consciência, e esta perda explica por que ele não move o "outro", ou o "segundo" lado do seu corpo. Espero, mais tarde, demonstrar que são explanações inválidas sobre estados materialísticos através de estados físicos.

Espero conseguir trazer aqui evidências para reforçar minhas opiniões de que todas as partes, de ambos os lados do corpo, são representadas em cada metade do cérebro. Esta visão é uma extensão da hipótese desenvolvida por Broadbent. Minha suposição é que os membros de ambos os lados são diferentemente representados em cada um dos hemisférios cerebrais, enquanto que os músculos de ação bilateral são quase igualmente representados em cada hemisfério cerebral. Evidências de que pelo menos algumas partes de ambos os lados do corpo estão representadas em cada um dos hemisférios cerebrais podem ser demonstradas quando há lesão de um lado da cápsula interna. Nesse caso, ocorre comprometimento das fibras nervosas “descendentes” em ambos os lados da medula espinhal.

Os graus de crises epilépticas ilustram as diferentes profundidades de dissolução. As crises têm várias apresentações, por exemplo, desde um espasmo no polegar e dedo indicador até a convulsão universal. Os graus de composição são bastante evidentes. O primeiro grau da crise é o comprometimento do braço; no segundo estágio, o braço é mais atingido e, a face, apenas um pouco; no terceiro estágio, o braço é o mais afetado, a face é bastante atingida e, a perna, apenas um pouco. Assim, a ordem composta do comprometimento, adequada à doutrina de localização, pode ser simbolizada $b$, no primeiro grau; $b^{2}+f$, no segundo e, no terceiro grau, $b^{3}+f^{2}+p$, etc. Estes casos necessitam de maiores 
esclarecimentos quanto à representação de ambos os lados do corpo, em cada hemisfério cerebral. As experiências de Franck e Pitres (Arch. de Phys., August 15, 1883, n. 6) levantam questões importantes sobre a dupla representação. Depois de exporem a chamada região motora dos hemisférios cerebrais do cachorro, removeram a região motora de um hemisfério e então estimularam a "região do braço" no hemisfério intacto (esquerdo) produzindo uma convulsão universal. Perceberam, também, que o espasmo seguia uma determinada ordem: primeiro o braço direito, depois a perna direita, seguida da perna esquerda e, por último, o braço esquerdo. "L’epilepsie peut donc se géneraliser malgré la destruction préalable de la zone motrice d'un côté, malgré la section longitudinal complète du corps calleux"5 (Franck e Pitres). Parece aqui evidente que ambos os lados do corpo estão representados em cada hemisfério cerebral, e que os dois lados estão diferentemente representados em cada hemisfério. Os respeitosos médicos franceses, aos quais me referi, fizeram a seguinte observação: "Le cerveau commence l'attaque, la protuberance, le bulbe, et la moelle la géneralisent.”6 Se assim for, mais uma vez fica provado que os movimentos de todo o corpo estão sob seu comando, totalmente representados pelos dois hemisférios cerebrais. Este é um assunto de extrema importância para a doutrina da evolução e dissolução. Torna-se evidente que os centros motores médios (nos quais as descargas iniciam crises epileptiformes) de cada metade do cérebro representam movimentos dos dois lados do corpo. Outros fatos, penso eu, apontarão que os centros motores mais superiores (lobos frontais) re-representam, por meio de combinações mais intricadas, tudo o que os centros motores médios representam de uma forma mais simples. Uma descarga iniciada nestes centros motores superiores mais evoluídos produz uma crise epiléptica que poderíamos chamar de "convulsão mais evoluída”.

5. “A epilepsia pode, pois, se generalizar apesar da destruição prévia da zona motora de um lado, apesar da secção longitudinal completa do corpo caloso”. (N. da T.)

6. “O cérebro inicia o ataque, a protuberância, o bulbo e a medula o generalizam”. (N. da T.) 